\title{
The Mogou Bioarchaeology Project: exploring health in the Chinese Bronze Age
}

Jenna M. Dittmarr, 2,* (D, Elizabeth S. Berger ${ }^{3}$, Ruilin Mao ${ }^{4}$, Hui Wang ${ }^{5}$ $\&$ Hui-Yuan Yeh $^{6}$

${ }^{1}$ McDonald Institute for Archaeological Research, University of Cambridge, UK

${ }^{2}$ Department of Archaeology, University of Aberdeen, UK

${ }^{3}$ Department of Anthropology, University of California, Riverside, USA

${ }^{4}$ Gansu Provincial Institute for Cultural Relics and Archaeology, Lanzhou, P.R. China

${ }^{5}$ Institute of Archaeological Science, Fudan University, P.R. China

${ }^{6}$ School of Humanities, Nanyang Technological University, Singapore

* Author for correspondence: $₫$ jenna.dittmar@abdn.ac.uk

Bioarchaeological research provides unique insights on human adaptation, diet, lifestyle and epidemiology. The Mogou Bioarchaeology Project explores how health was affected by the Bronze Age transition in north-west China. Preliminary results reveal that the inhabitants experienced substantial physiological stress, infectious disease and lethal trauma.

Keywords: China, Bronze Age, bioarchaeology, human adaptation

The second millennium BC in north-west China was characterised by a drastic period of climate change, technological exchange and social upheaval. Our understanding of how human cultures were affected by and adapted to the change in climate and environmental deterioration that occurred during the Bronze Age transition can be further understood through bioarchaeological research. To distinguish the impact of environmental and social stresses on the health of ancient communities, the Mogou Bioarchaeology Project was established in 2015 by a team of international scholars and the Gansu Provincial Institute of Cultural Relics and Archaeology (Figure 1). The main aim of the project is to understand the impact of social, technological and environmental factors on human demography, health and lifeways during the Bronze Age.

The human skeletal remains under analysis were recovered from the cemetery site of Mogou (磨沟) in Lintan County, Gansu Province (Figure 2). The cemetery is located on a terrace above the south-west bank of the Tao River, covers more than 30 ha and yielded a total of 1688 graves. The site was discovered prior to the construction of a reservoir and was completely excavated between 2008 and 2012 by the Gansu Provincial Institute of Cultural Relics and Archaeology and the School of Cultural Heritage of Northwest University. All excavated materials are currently stored at the Gansu Institute's headquarters in the provincial capital of Lanzhou. Initially it was estimated that over 4000 individuals were

Received: 17 April 2020; Revised: 16 August 2020; Accepted: 19 August 2020

(C) The Author(s), 2021. Published by Cambridge University Press on behalf of Antiquity Publications Ltd. This is an Open Access article, distributed under the terms of the Creative Commons Attribution licence (http://creativecommons. org/licenses/by/4.0/), which permits unrestricted re-use, distribution, and reproduction in any medium, provided the original work is properly cited. 


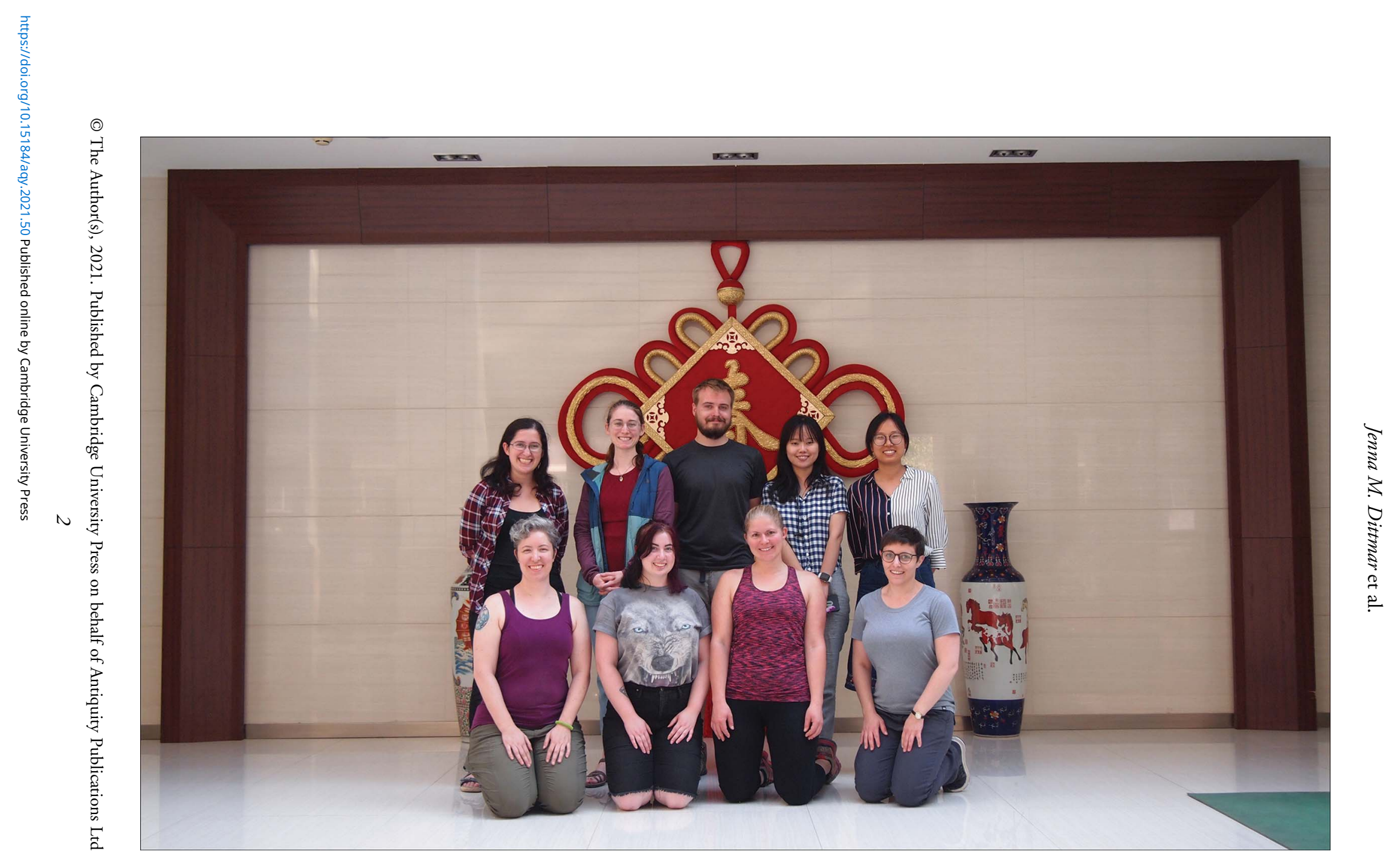

Figure 1. The 2019 field team of the Mogou Bioarchaeology Project at the Gansu Provincial Institute of Cultural Relics and Archaeology, Lanzhou, China (photograph by D. Hansen). 


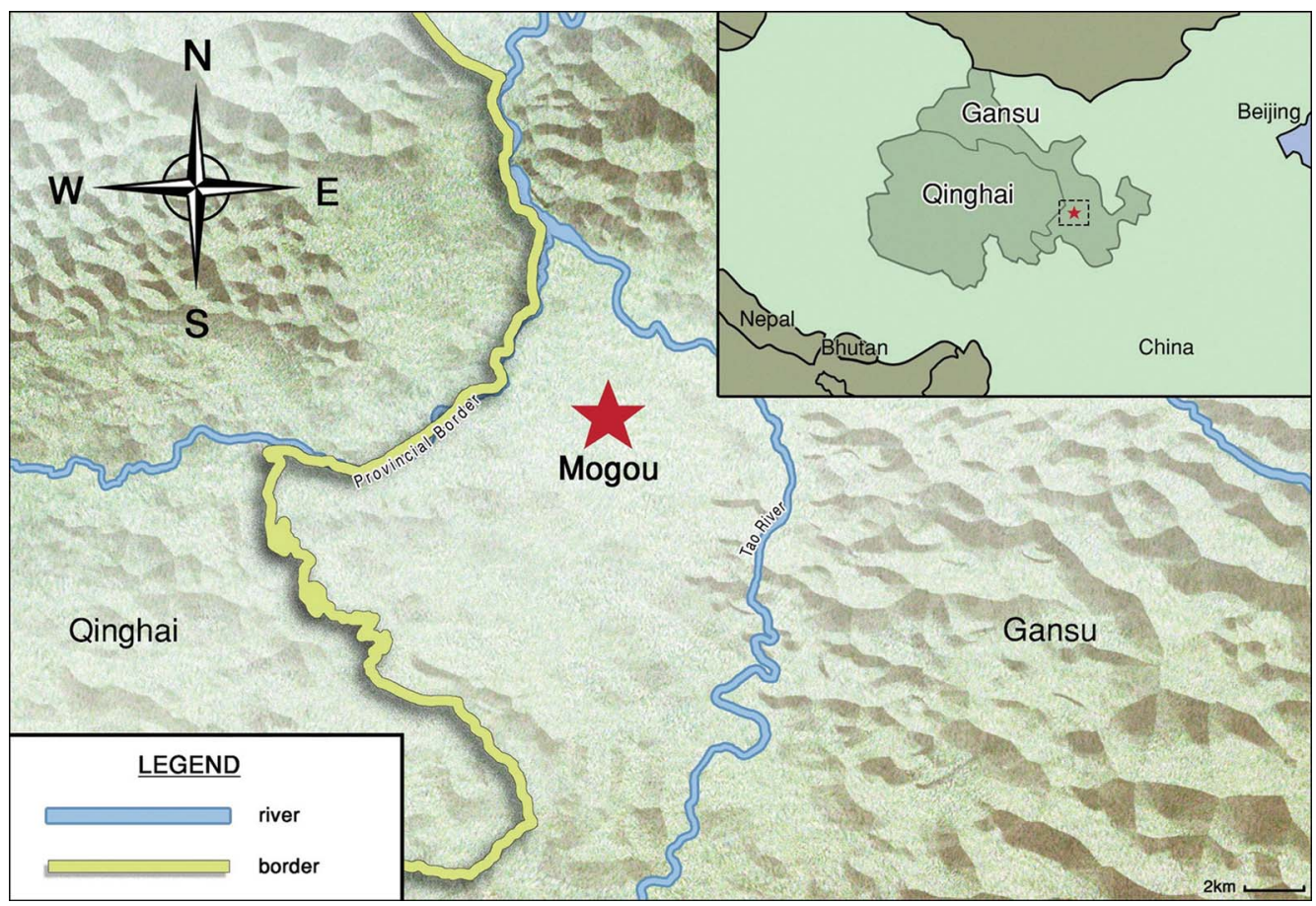

Figure 2. Map showing the modern borders of Gansu Province and the location of the Mogou site, Lintan County, Gansu (map by Chuan Zhu, Nanyang Technological University).

entombed in this cemetery, but based on our analysis of commingled remains, particularly infants, we now believe that the number of individuals present exceeds 5000. Radiocarbon dates indicate that the site was in use between 1750 and $1100 \mathrm{BC}$, and the grave goods suggest it was used to inter individuals associated with the Qijia material culture complex from 1750-1400 BC, and later with the Siwa material culture from 1400-1100 BC (Mao et al. 2009; Xie et al. 2009).

The Qijia Culture dates from the Early and Middle Bronze Age, and is found throughout north-west China, including the western Loess Plateau, the eastern Hexi Corridor, the eastern Qinghai Plateau and throughout the upper Yellow River Valley and its tributaries (Xie 2002; Mao et al. 2009; Xie et al. 2009; Chen 2013). This is the region through which many elements of material culture and technology were exchanged between North Asia, Central Asia and China (Liu \& Chen 2012; Campbell 2014; Womack et al. 2017). Qijia Culture sites also represent diverse subsistence strategies, including agriculture and animal husbandry. Thus, they are critical for understanding the subsistence shift towards a greater reliance on pastoralism during the second millennium BC in north-west China.

The Siwa Culture was a Late Bronze Age material culture complex also associated with mixed agropastoral food production, found in eastern Gansu and the upper Yellow River drainage (Xie 2002). The skeletal remains from the Siwa graves are still under analysis, and will provide a critical temporal comparative sample for the Qijia remains in future analyses.

(C) The Author(s), 2021. Published by Cambridge University Press on behalf of Antiquity Publications Ltd 


\section{Preliminary findings}

Over the course of five field seasons, 757 individuals have been analysed. The majority of these individuals $(n=665)$ are from graves associated with the Qijia material culture, while far fewer individuals $(\mathrm{n}=92)$ are from graves identified by excavators as belonging to the Siwa Culture. Macroscopic and radiographic analyses have provided evidence that the individuals buried in the cemetery experienced a range of specific and non-specific infectious, metabolic and congenital illnesses (e.g. tuberculosis, scurvy, osteoporosis, ankylosing spondylitis) (Figure 3). Analysis of the latest findings is ongoing, but previous research on the Qijia individuals revealed evidence of cranial surgery (Dittmar et al. 2019a), as well as substantial evidence of lethal violence, primarily on male individuals (Figure 4) (Dittmar $e t$ al. 2019b).

Although the Mogou burials are mostly multiple interments, severe commingling was primarily limited to sub-adult skeletons, and in adult skeletons was generally of only a few elements, so analysis by individual was possible in most cases. The baseline of the chronic but non-fatal disease burden in the Qijia population was assessed by analysing skeletal lesions that are associated with physiological stress, which can result from poor nutrition, infectious disease, parasitic infection and repeated growth insults in childhood, among other causes. Indicators of stress include dental enamel hypoplasia (defects in tooth enamel that result from growth disruptions during childhood), cribra orbitalia (porosity on the orbital roof), porotic hyperostosis (porosity on the cranial vault) and periosteal new bone formation on the long bones. Analysis of the well-preserved (over 25 per cent complete) and non-commingled individuals $(n=417)$ revealed that 43 per cent $(n=53 / 123)$ of those with teeth present had dental enamel hypoplasia in two or more teeth. Thirty-two per cent $(n=77 / 243)$ of individuals had cribra orbitalia, 7 per cent $(n=19 / 263)$ had porotic hyperostosis, and 55 per cent $(n=$ 167/306) had evidence of healed or healing periosteal reaction on the appendicular skeleton. These findings indicate that the people interred at Mogou experienced substantial chronic physiological stress. Thirteen per cent $(n=41 / 306)$ of individuals had evidence of active periosteal reaction, indicating that they died while experiencing physiological stress possibly caused by a nutritional deficiency, trauma or an infection.

\section{Going forward}

The preliminary findings of this project indicate that the people interred at Mogou likely consumed nutritionally inadequate diets and experienced chronic physiological stress throughout their lives. The factors that contributed to this high morbidity, and how it relates to the presence of infectious diseases and lethal violence, will be further explored by the members of the project over the next five years. The next phase of research at Mogou has three primary aims. The first is to expand the sample size and use hazard analysis to identify trends in morbidity, fertility and mortality over time that may be associated with social or environmental changes. The second aim is to identify and analyse infectious disease lesions to understand further the disease landscape. This will be done in collaboration with scholars from Fudan University's Institute of Archaeological Science, who will conduct ancient DNA analysis to identify pathogens. The third aim is to identify correlates of violence at the site in order to understand 


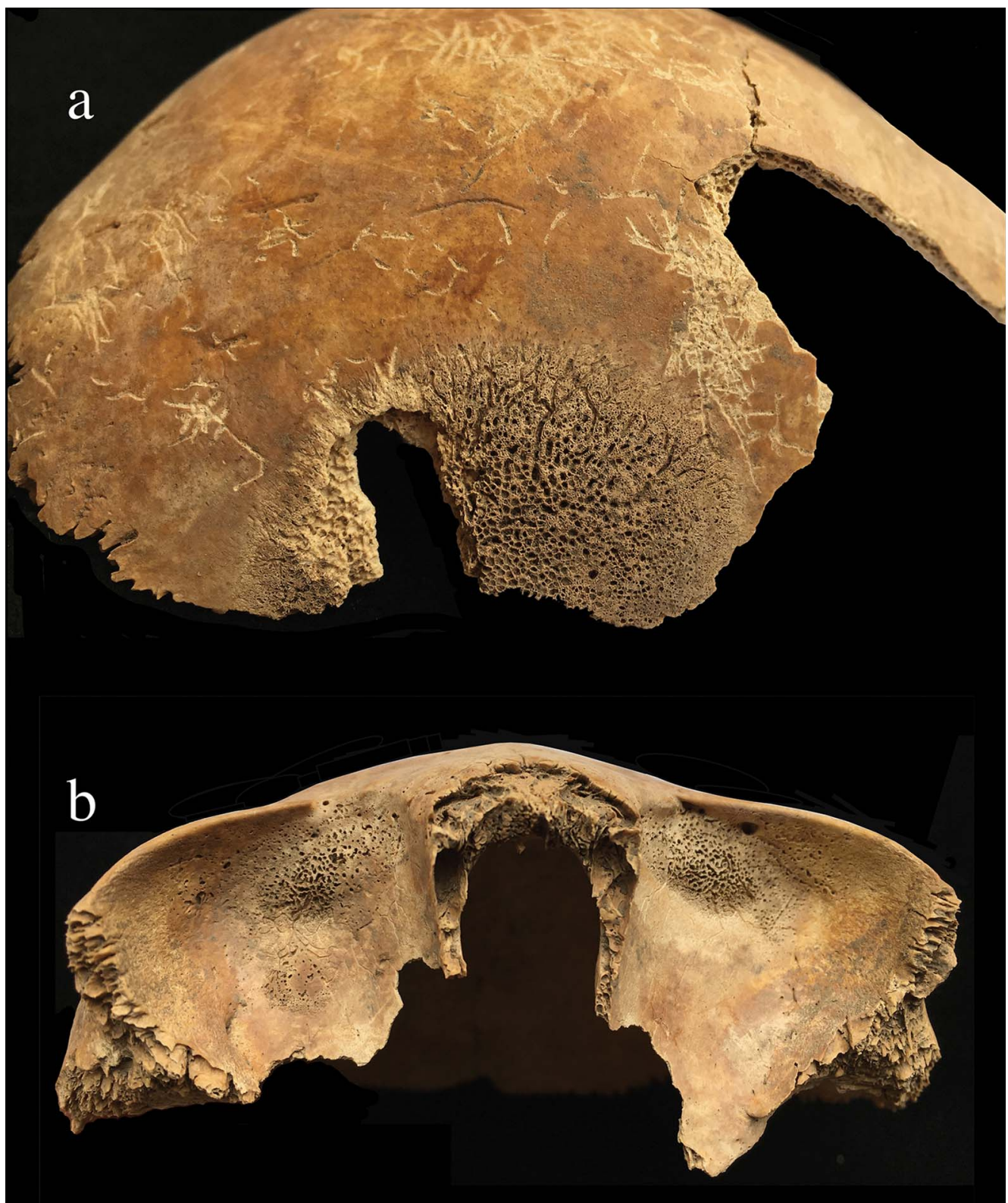

Figure 3. Osteological lesions consistent with scurvy present on a non-adult individual: a) porotic hyperostosis on the right parietal bone; b) new woven bone formation on the roof of each orbit, with abnormal pitting (photographs by J. Dittmar).

the causes of intergroup conflict in Bronze Age north-west China. These findings will be contextualised using the Gansu Institute's ongoing seriation and analysis of the material culture from the site. This will then enable us to explore how social, technological and environmental factors influenced demography, health and the human experience during the second millennium BC.

(C) The Author(s), 2021. Published by Cambridge University Press on behalf of Antiquity Publications Ltd 


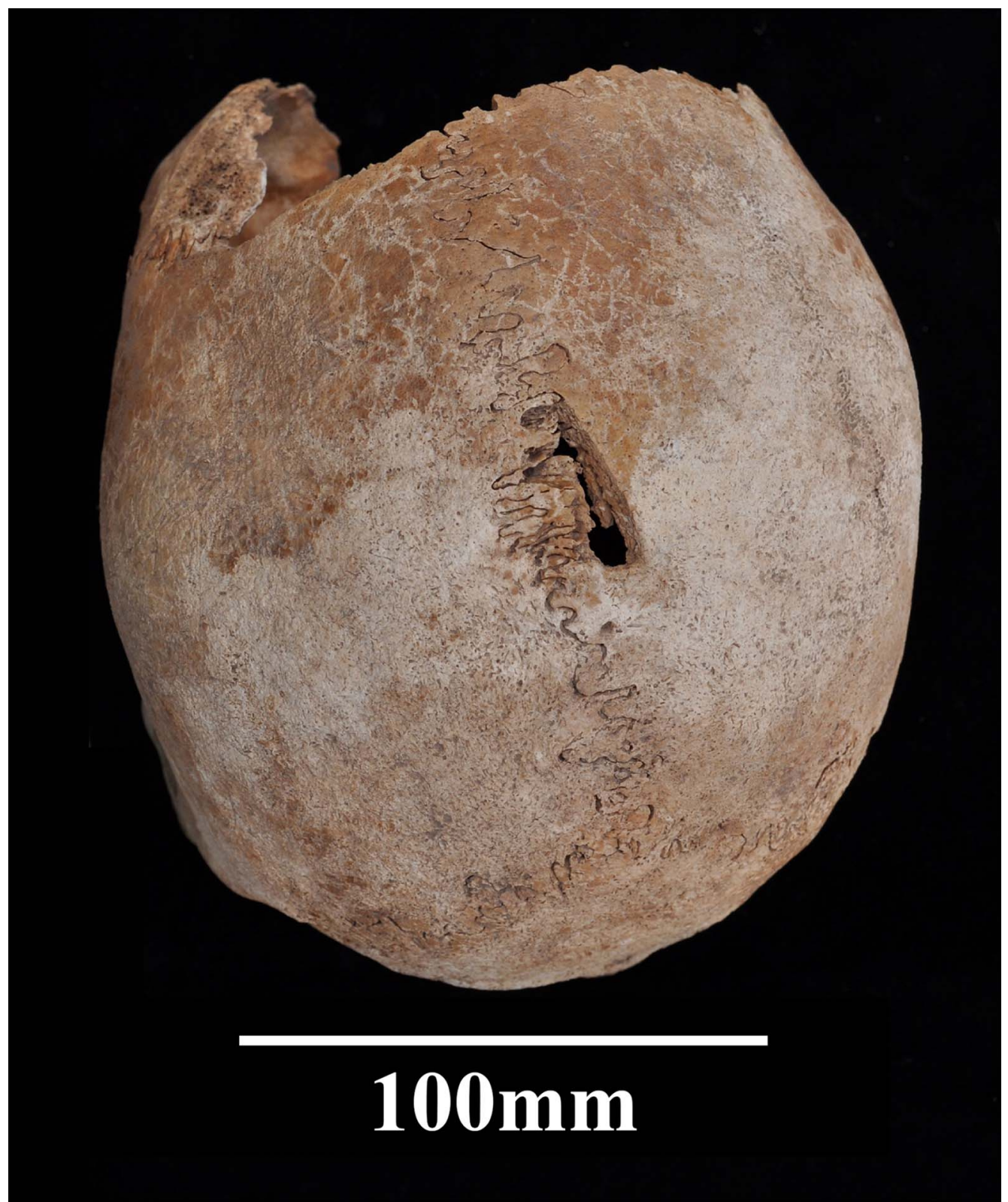

Figure 4. Peri-mortem trauma located on the cranium of an adult male individual from the Mogou site (M448 R3) (photograph by J. Dittmar).

\section{Acknowledgements}

The authors would like to thank all of the students who have volunteered to work on the Mogou Bioarchaeology Project, the staff at the Gansu Provincial Institute of Cultural Relics and Archaeology for their invaluable support and assistance during data collection, and the anonymous reviewers for their comments on this manuscript.

(C) The Author(s), 2021. Published by Cambridge University Press on behalf of Antiquity Publications Ltd 


\section{Funding statement}

Funding to carry out this research was provided by the Centre for Liberal Arts and Social Sciences, Nanyang Technological University, Singapore; Chinese National Social Science Key Project Grant for The Mogou Cemetery Project: Multidisciplinary Research in Gansu Lintan (grant number: 18ZDA225); Banco Santander through the Santander Mobility Grant scheme at the University of Cambridge; Darwin College, Cambridge; the LieberthalRogel Center for Chinese Studies at the University of Michigan; the Esherick-Ye Family Foundation; the Association for Asian Studies China and Inner Asia Council; and the American Association of Physical Anthropologists Cobb Professional Development Grant programme.

\section{References}

Campbell, R. 2014. Archaeology of the Chinese Bronze Age: from Erlitou to Anyang. Los Angeles (CA): Cotsen Institute of Archaeology Press. https://doi.org/10.2307/j.ctvdjrr9r

Chen, H. 2013. The Qijia Culture of the upper Yellow River Valley, in A.P. Underhill (ed.) $A$ companion to Chinese archaeology: 105-24. Chichester: Blackwell.

Dittmar, J., X. Zhan, E. Berger, R. Mao, H. Wang, Y. ZhaO \& H.-Y. YeH. 2019a. Ritualistic cranial surgery in the Qijia Culture (2300-1500 BCE), Gansu, China. Acta Anthropologica Sinica 38: 389-97.

Dittmar, J., E. Berger, X. Zhan, R. MaO, H. WANG \& H.-Y. YEH. 2019b. Skeletal evidence of violent trauma from the Bronze Age Qijia Culture (2300-1500 BCE), Gansu Province, China. International Journal of Paleopathology 27: 66-79. https://doi.org/10.1016/j.ijpp.2019.08.002

Liu, L. \& X. Chen. 2012. The archaeology of China: from the Late Paleolithic to the Early Bronze Age.
Cambridge: Cambridge University Press. https://doi.org/10.1017/CBO9781139015301 MaO, R., Y. Qiang, Y. Xie, Y. Zhu \& J. Zhou. 2009. Gansu Lintan Mogou Qijia wenhua mudi fajue jianbao [Brief report on the excavation of Qijia graves at the Mogou cemetery, Lintan, Gansu]. Wenwu, 641: 10-24.

Womack, A., Y. Jaffe, J. Zhou, L.-Y. Hung, H. Wang, S. Li, P. Chen \& R. Flad. 2017. Mapping Qijiaping: new work on the type-site of the Qijia Culture (2300-1500 BC) in Gansu Province, China. Journal of Field Archaeology 42: 488-502. https://doi.org/10.1080/00934690.2017.1384669

XIE, D. 2002. Ganqing Diqu Shiqian Kaogu (Prehistoric archaeology of Gansu and Qinghai). Beijing: Wenwu chubanshe.

Xie, Y., Y. Qiang, R. Mao, J. Zhou \& Y. Zhu. 2009. Gansu Lintan xian Mogou Qijia wenhua mudi [A Qijia cultural cemetery, Mogou in Lintan County, Gansu Province]. Kaogu 49(7): $10-17$. 